\title{
Corpo feminino e envelhecimento na obra de Lygia Fagundes Telles
}

\author{
Female body and aging \\ in the work of Lygia Fagundes Telles \\ Cuerpo femenino y envejecimiento \\ en la obra de Lygia Fagundes Telles
}

Maria do Rosário A. Pereira*

\section{Resumo}

O objetivo deste artigo é dar visibilidade aos diversos modos de representação do corpo envelhecido na obra da escritora Lygia Fagundes Telles, comparando tais imagens com outras apresentadas por Clarice Lispector e Maria Valéria Rezende. Seguindo os rastros deixados por Elódia Xavier em Que corpo é esse?, buscamos traçar uma espécie de tipologia do próprio corpo envelhecido, a fim de demonstrar a diversidade de suas representações na literatura de autoria feminina. Neste texto, propomos investigar o corpo envelhecido da seguinte forma: i) o corpo envelhecido como degradação; ii) o corpo envelhecido silenciado; iii) o corpo envelhecido redimido. Tais escritoras apontam, assim, o quão difícil se torna o envelhecimento em uma sociedade que confina o idoso a situações degradantes tanto em âmbito familiar quanto público.

Palavras-chave: corpo envelhecido, Lygia Fagundes Telles, literatura de autoria feminina, literatura comparada.

\section{Abstract}

The objective of this paper is to give visibility to the different modes of representation of the aged body in the work of the writer Lygia Fagundes Telles, comparing such images with others presented by Clarice Lispector and Maria Valéria Rezende. Following in the footsteps of Elódia Xavier in Que corpo é esse?, we sought to delineate a kind of typology of the aged body itself, in order to demonstrate the diversity of its representations in works by female authors. In this text, we propose to investigate the aged body as follows: i) the aged body as degradation; ii) the silenced aged body; iii) the redeemed aged body. With their work, these female writers point out how difficult aging becomes in a society that confines the elderly to degrading situations both in domestic and public spheres.

Keywords: aged body, Lygia Fagundes Telles, female authorship, comparative literature.

\begin{abstract}
Resumen
El objetivo de este artículo es dar visibilidad a los diversos modos de representación del cuerpo envejecido en la obra de la escritora Lygia Fagundes Telles, comparando tales imágenes con otras presentadas por Clarice Lispector y Maria Valéria Rezende. Siguiendo los rastros dejados por Elódia Xavier en Que corpo é esse?, buscamos trazar una especie de tipología del propio cuerpo envejecido, a fin de demostrar la diversidad de las representaciones de ese cuerpo en la literatura de autoría femenina. En este texto, proponemos investigar el cuerpo envejecido de la siguiente forma: i) el cuerpo envejecido como degradación; ii) el cuerpo envejecido silenciado; iii) el cuerpo envejecido redimido. Tales escritoras apuntan, así, cuán difícil se torna el envejecimiento en una sociedad que confina el anciano a situaciones degradantes tanto en el ámbito familiar como público.
\end{abstract}

Palabras clave: cuerpo envejecido, Lygia Fagundes Telles, literatura de autoría femenina, literatura comparada.

\footnotetext{
* Doutora em literatura brasileira e professora do Centro Federal de Educação Tecnológica de Minas Gerais (CEFET-MG), Belo Horizonte, MG, Brasil. Dorcid.org/0000-0002-4797-5724. E-mail: mariadorosario58@gmail.com.
} 


\section{Representações do corpo envelhecido}

O envelhecimento feminino é um assunto tabu na sociedade. Basta um rápido olhar sobre as propagandas para nos darmos conta de que estamos imersos em uma sociedade que supervaloriza o corpo e a juventude em detrimento de corpos maduros e, sobretudo, envelhecidos. Comerciais estereotipados como os de cerveja demonstram isso, ao exibirem mulheres seminuas com corpos extremamente bem definidos. Conforme aponta Simone de Beauvoir em $A$ velhice, ao se falar de velhos na história da humanidade, fala-se, sobretudo, de homens velhos, já que as mulheres não estão em evidência nos registros mais antigos sobre o envelhecimento humano. "Já que o destino da mulher é ser, aos olhos do homem, um objeto erótico, ao tornar-se velha e feia, ela perde o lugar que lhe é destinado na sociedade" (Beauvoir, 1990, p. 152). No entanto, conforme destaca a própria Beauvoir, a condição do velho é dependente do contexto em que ele está inserido. Também Eclea Bosi, em Memória e sociedade: lembranças de velhos, parte do mesmo princípio, ao pontuar que "além de ser um destino do indivíduo, a velhice é uma categoria social. Tem um estatuto contingente, pois cada sociedade vive de forma diferente o declínio biológico do homem" (Bosi, 1987, p. 77).

Conforme Beauvoir, ao longo da história a humanidade encarou a velhice entre dois polos, de acordo com os interesses e as necessidades do momento: ora o idoso era visto como digno de respeito, simbolizando cultura e experiência adquiridas, ora era visto como digno de desprezo e mesmo escárnio - haja vista a representação do velho avarento que perdurou durante um certo período, sendo possível encontrar vestígios dessa representação na própria literatura, por exemplo.

No que se refere ao Brasil, como este se insere numa cultura capitalista, se o indivíduo é improdutivo, é relegado a segundo plano. Esta herança é fruto do advento da revolução industrial, a qual deixou como legado a preocupação unicamente com a rentabilidade que as pessoas podem gerar. Paradoxalmente, houve uma alteração nas últimas décadas na pirâmide populacional brasileira, seguindo um fenômeno mundial. De acordo com documento da Secretaria de Direitos Humanos da Presidência da República, "uma das maiores conquistas culturais de um povo em seu processo de humanização é o envelhecimento de sua população" (Brasil, 2014, p. 1). O número de idosos no Brasil dobrou nos últimos 20 anos, conforme IBGE. Ainda de acordo com o documento citado acima, nota-se uma "feminilização da velhice", isto é, o número de mulheres com mais de 60 anos já ultrapassou o de homens. Tal longevidade, no entanto, não vem acompanhada de uma mudança na mentalidade sobre o assunto, de um reconhecimento efetivo dos direitos e da dignidade dos idosos. São frequentes os atos de desrespeito à população idosa, em vagas preferenciais ou em filas de banco. Isso sem levar em consideração muitos outros direitos assegurados por lei, mas ainda distantes na prática.

Em relação ao corpo feminino, especificamente, há uma cobrança da sociedade para que os padrões de beleza e jovialidade sejam mantidos. Somos a todo momento bombardeadas com propagandas que exaltam a beleza e a forma física e impelidas a realizar cirurgias plásticas para moldar o corpo conforme padrões estabelecidos. É interessante notar que, no que se refere à sexualidade, a ótica com que o envelhecimento masculino é observado é contrária ao do corpo feminino. Envelhecer, para o homem, significa adquirir experiência, maturidade, a qual pode reforçar, inclusive, a aura de sedutor com que é retratado em várias produções culturais, sobretudo televisivas e cinematográficas, haja vista o grande número de galãs de terceira idade no cinema hollywoodiano e nas novelas brasileiras, por exemplo. Homens mais velhos relacionandose com mulheres mais jovens não é uma situação que causa espanto, mas, se uma mulher mais velha relaciona-se com um homem mais novo, isso nos leva a pensar, invariavelmente, em exploração financeira, uma vez que, aos olhos da sociedade capitalista e hedonista, ela já não tem mais nada a oferecer a alguém. De acordo com Regina Dalcastagnè, em "A personagem do romance brasileiro contemporâneo: 1990-2004", há relativa baixa presença de mulheres adultas e maduras no romance brasileiro atual e, quando as há, o enfoque recai sobre "o casal romântico formado pelo galã maduro e pela mulher muito mais jovem" (Dalcastagnè, 2005, p. 38). Para Marilena Chaui, em Repressão sexual: essa nossa (des)conhecida, esse clichê reforça "a condenação que pesa sobre as mulheres cujos parceiros são mais jovens e conserva o elogio dos homens que 
conseguem parceiras mais jovens" (Chaui, 1984, p. 206). Sendo assim, é premente investigar representações que, de alguma forma, problematizem essas dicotomias.

O corpus aqui selecionado foi determinado, primeiramente, por uma questão de fundo teórico, a saber, a definição que Giorgio Agamben faz acerca do que é o contemporâneo em sua conhecida obra O que é o contemporâneo? e outros ensaios. Partindo de Agamben, indagamos: de quem e do que somos contemporâneos? E o que significa ser contemporâneo? Agamben define da seguinte forma:

Pertence verdadeiramente ao seu tempo, é verdadeiramente contemporâneo, aquele que não coincide perfeitamente com este, nem está adequado a suas pretensões e é portanto, nesse sentido, inatual; mas, exatamente por isso, exatamente através desse deslocamento e desse anacronismo ele é capaz, mais do que os outros, de perceber e apreender o seu tempo (Agamben, 2009, p. 58-59).

Paradoxalmente, para conseguir ver, debruçar-se sobre o seu próprio tempo, deve-se dele se distanciar - tal o deslocamento a que remete o filósofo italiano. Pensando nessa definição e no papel do escritor, este é muitas vezes voz dissonante na sociedade, capaz de enxergar o seu tempo, então, sob um viés crítico, numa "singular relação com o próprio tempo" (Agamben, 2009, p. 59). É sob esse conceito de contemporâneo que se justifica o recorte deste trabalho, o qual procura apresentar imagens na obra de Lygia Fagundes Telles de corpos femininos em processo de envelhecimento, comparando essas imagens com as que aparecem na obra de outras escritoras, a saber, Clarice Lispector e Maria Valéria Rezende. O objetivo é dar visibilidade a tais textos e, também, aos diversos modos de representação com que a velhice se apresenta. Por isso, priorizam-se escritoras que traduziram, literariamente, imagens desse corpo feminino desprezado socialmente, mostrando ao leitor, de forma contundente e nada tácita, o quão difícil se torna o envelhecimento em uma sociedade que confina o idoso a situações degradantes tanto em âmbito familiar quanto em âmbito público.

Ressalte-se que "o corpo envelhecido" já é uma categoria teórica estudada, por exemplo, por Elódia Xavier em sua tipologia de corpos exposta no livro Que corpo é esse? O corpo no imaginário feminino (2007). Sendo assim, selecionamos alguns contos de Lygia Fagundes Telles e Clarice Lispector, e faremos um breve comentário sobre os romances As horas nuas e Quarenta dias, respectivamente de Fagundes Telles e Maria Valéria Rezende. Seguindo os rastros deixados por Xavier, buscamos traçar uma espécie de tipologia do corpo envelhecido, a fim de demonstrar quão diversas são as representações desse corpo na literatura de autoria feminina, ainda que haja pontos de confluência nestas representações. Em Que corpo é esse?, por meio do estudo de 23 narrativas, Elódia Xavier investiga como o corpo feminino é retratado na literatura contemporânea escrita por mulheres, abordagem esta que passa pela invisibilidade social, pela disciplinarização, pela violência, pelo erotismo, e, também, pelo envelhecimento, dentre outras categorias. Neste texto, propomos investigar o corpo envelhecido da seguinte forma: i) o corpo envelhecido como degradação; ii) o corpo envelhecido silenciado; iii) o corpo envelhecido redimido. Saliente-se que a proposição dessas categorias analíticas não é estanque nem tampouco contempla o rol de possibilidades de leitura que se afigura no corpus aqui estudado. Tais categorias apenas buscam iluminar alguns aspectos pertinentes à questão aqui tratada.

\section{O corpo envelhecido como degradação}

Em As horas nuas, romance de Lygia Fagundes Telles publicado em 1989, tem-se como protagonista Rosa Ambrósio, uma atriz decadente que alimenta o desejo de escrever suas memórias. Quase sempre acometida por excessos alcoólicos, tem por companhia fiel o gato Rahul, um dos narradores do romance ao lado dela e de um terceiro narrador heterodiegético. $\mathrm{O}$ leitor tem, assim, acesso às reminiscências de Rosa, sobretudo quanto a seus dilemas internos e a seus amores perdidos, como um primo que morrera de overdose; Gregório, o marido que se suicida após ser torturado nos anos de chumbo; e Diogo, o secretário que se torna seu amante. Por meio de várias passagens, nota-se o quanto o processo de envelhecimento é árduo para a personagem. Interessante observar como a própria Rosona, como era chamada por Rahul, referenda o preconceito com que a sociedade enxerga os mais 
velhos, pois recrimina o fato de sua filha, Cordélia, relacionar-se somente com "velhos": "Nem quinze anos tinha Cordélia! e já começou a sair com a homenzarada. Tudo velho... Eu queria apenas uma filha normal - seria pedir muito? Podia ser livre, morar longe com sua tropa de amantes, aceito. Mas não precisava ser uma tropa de velhos" (Telles, 1999a, p. 89).

O corpo degradado vai se delineando aos olhos do leitor: há o reconhecimento de uma situação para a qual não há solução, ainda que a personagem lute contra isso, por isso oscila entre aceitação e negação: "Tantos espelhos. Mas só agora me vejo, uma frágil mulher cheia de carências e aparências, dobrando o Cabo da Boa Esperança, já nem sei que Cabo é esse, era a mamãe que falava nisso mas deve ter alguma relação com a velhice, ô! meu Pai, que palavra desprezível" (Telles, 1999a, p. 12). Narcisista, Rosa tem medo de envelhecer. Como nosso inconsciente alimenta a ilusão da eterna juventude, quando essa ilusão se quebra devido à realidade, o sujeito se vê diante de um "traumatismo narcísico que gera uma psicose depressiva" (Beauvoir, 1990, p. 358). É exatamente esse o ponto em que se apresenta a personagem Rosa Ambrósio: "estou ficando velha e me ralo de inveja dos jovens... Também quis segurar a beleza, quem não?... Mas ela escapou por entre meus dedos, água... Quero de volta a minha juventude!" (Telles, 1999a, p. 101). A juventude representa, assim, o tempo idílico, no qual tudo era possível, pensamento semelhante ao da personagem Luisiana, do conto "Apenas um saxofone", também de Fagundes Telles, no qual a protagonista se lembra de ter mandado embora um amor de juventude para se casar com um velho rico. Como Rosona, Luisiana se degrada por meio do álcool, numa impossibilidade de reconfigurar sua vida.

É tal a preocupação de Rosona em parecer jovem que o gato Rahul narra uma cena grotesca, em que ela tinge seus pelos pubianos:

Não sei por que esses bandidos tinham que nascer brancos, resmungou ela. Já estava de luvas quando mergulhou mais uma vez a escova na tintura do copo. [...] Abriu as pernas e bem devagar foi passando a tinta nos pelos do púbis. Com a mão livre, abriu a caixa rosada no tampo de mármore e dela tirou um lenço de papel para limpar o fio de tinta negra que the escorria pela coxa, Ô, meu Pai! (Telles, 1999a, p. 33).

Como se nota, a relação com o corpo se torna problemática; conforme Beauvoir, na medida em que a relação do indivíduo com o tempo se modifica, modifica-se também a relação com sua própria história e com o mundo que nos cerca. A não aceitação de Rosa Ambrósio de um processo que é absolutamente previsto e natural faz com que ela recorra a alguns subterfúgios, como o álcool e inúmeras tentativas vãs de manter a jovialidade do corpo físico. Para a protagonista, a velhice é "a pior das doenças", e aqueles que a cercam conseguem perceber isso. No excerto a seguir, é Diogo quem desmascara a situação:

- É simples, Rosa, escuta, você está em pânico porque sente que está envelhecendo. [...] Rosa Ambrósio, como vou fazer entrar nessa cabeça que não existe outra saída, existe? Para escapar da velhice, querida, só morrendo jovem mas agora não dá mais. A solução é enfrentar sem fazer bico, de bom humor, se possível (Telles, 1999a, p. 112).

No entanto, a não aceitação de Rosa acaba conduzindo-a, paulatinamente, à solidão. Solidão esta que também parece ser o destino da personagem Alice, do conto "A ceia". Nesse conto cujo título remete claramente à última ceia bíblica -, tem-se o derradeiro encontro de Alice e Eduardo, seu ex-companheiro que, agora, está prestes a se casar com uma mulher mais jovem. É interessante notar que esse fato social tão conhecido - a troca de mulheres mais velhas por mulheres mais jovens - é trabalhado por Fagundes Telles mais de uma vez em sua ficção. Exemplo disso é o sugestivo conto "Um chá bem forte e três xícaras", em que Maria Camila aguarda a estagiária de dezoito anos do marido para tomarem um chá. Devido a uma série de pistas o leitor é levado a crer que se trata de um caso extraconjugal, mas o conto termina com a protagonista dirigindo-se à porta para receber a jovem. Em mais um de seus finais enigmáticos, fica a cargo do leitor inferir ou, principalmente, imaginar o desfecho da situação.

Voltando ao conto "A ceia", a mesa com pouca iluminação, na primeira cena, o fato de Alice apagar o abajur e, ainda, detestar o isqueiro que o homem acende em diversos momentos apontam para o fato de que ela não quer ser vista, ou melhor, não quer que 
Eduardo se dê conta de seu envelhecimento. A personagem faz de tudo para parecer mais jovem como, por exemplo, o corte de cabelo novo que é por ele observado, cujo objetivo era remoçar. Além disso, em determinado momento, indaga acerca de Lili, a noiva de Eduardo: "E já sabe tudo a meu respeito, não? Até minha idade" (Telles, 1999b, p. 114). Num diálogo tenso e regado a vinho, Alice perde a compostura a pouco e pouco. Chega a implorar que ele a visite ao menos de vez em quando. A diferença de idade fica evidente ao final do conto, quando, após discutirem, Eduardo vai embora e Alice fica sozinha. Indagada pelo garçom sobre se estava se sentindo bem, este arremata: "Também discuto às vezes com a minha velha, mas depois fico chateado à beça. Mãe sempre tem razão" (Telles, 1999b, p. 122).

Assim, tanto Rosa Ambrósio quanto Alice lutam contra o envelhecimento relacionando-se com pessoas mais jovens; no entanto, acaba restando-lhes a fuga pelo álcool e a solidão.

\section{O corpo envelhecido silenciado}

Em "Feliz aniversário", de Clarice Lispector, publicado em Laços de família, filhos, noras e netos encontram-se reunidos para celebrar os 89 anos de D. Anita. Já no início do conto nota-se uma família esfacelada, com irmãos que não se entendem e comparecem à festividade apenas por obrigação. O que deveria ser um momento de confraternização torna-se um momento de mera convenção social, no qual a aniversariante é a figura menos importante. $\mathrm{O}$ narrador a descreve como se fosse um móvel velho esquecido na sala ou um enfeite de somenos importância, num índice claro de desumanização da personagem:

[...] para adiantar o expediente, [Zilda] vestira a aniversariante logo depois do almoço. Pusera-lhe desde então a presilha em torno do pescoço e o broche, borrifara-lhe um pouco de água-de-colônia para disfarçar aquele seu cheiro de guardado - sentara-a à mesa. $\mathrm{E}$ desde as duas horas a aniversariante estava sentada à cabeceira da longa mesa vazia, tesa na sala silenciosa (Lispector, 2016, p. 180).

Adiante, o narrador afirma que ela estava era "posta à mesa", e que "parecia oca", novos elementos que apontam sua objetificação. Além disso, é marcante o silêncio com que a aniversariante reage à chegada dos familiares e aos comentários sobre sua idade, o que é reforçado pelo recurso da repetição de "A velha não se manifestava", quase como um refrão a reiterar sua impassibilidade. Quando chamada a cortar o bolo, ela o faz "com punho de assassina", e a alusão à morte, ao enterro social da personagem - há muito esquecida por aquela parentada que não a visitava, não colaborava financeiramente com sua situação e, menos ainda, lhe dedicava qualquer afeto - fica ainda mais evidente na passagem a seguir: "Dada a primeira talhada [no bolo], como se a primeira pá de terra tivesse sido lançada, todos se aproximaram de prato na mão, insinuando-se em fingidas acotoveladas de animação, cada um para a sua pazinha" (Lispector, 2016, p. 184).

A tensão cresce, e, internamente, D. Anita se pergunta por que logo ela, que havia sido um tronco vigoroso, dera "aqueles azedos e infelizes frutos [...] seres risonhos, fracos, sem austeridade", o que culmina em uma atitude que cria a expectativa no leitor de uma reviravolta: "Incoercível, virou a cabeça e com força insuspeita cuspiu no chão" (Lispector, 2016, p. 185). Após essa atitude, ela, até então muda durante toda a festa, manifesta-se pede um copo de vinho -, e sua impassibilidade se transfere para os filhos, estupefatos diante das reações aparentemente intempestivas da mãe:

- Vovozinha, não vai lhe fazer mal? insinuou cautelosa a neta roliça e baixinha.

- Que vovozinha que nada! explodiu amarga a aniversariante. -Que o diabo vos carregue, corja de maricas, cornos e vagabundas! me dá um copo de vinho, Dorothy! - ordenou (Lispector, 2016, p. 186).

No entanto, o que parecia ser uma tragédia anunciada, não se concretiza, e a velha volta à mesma posição anterior. Somente Cordélia, uma das noras, parece refletir: "É preciso que se saiba. É preciso que se saiba. Que a vida é curta. Que a vida é curta" (Lispector, 2016, p. 189). 
Assim, D. Anita em nada condiz com a imagem da "boa velhinha", da "vovozinha" sempre pacata a submeter-se às vontades daqueles que lhes rodeiam. Apesar de sua dependência econômica e suas limitações físicas, não deixa de dar seu recado. Beauvoir salienta que o adulto, de maneira dissimulada, "tiraniza o velho que depende dele", e a este velho são impostas regras de conduta que passam pelo vestuário, "uma decência de maneiras, e um respeito às aparências" (Beauvoir, 1990, p. 54). Muitas vezes, atitudes consideradas estranhas por parte dos velhos, como descuidos em relação à higiene, por exemplo, nada mais são do que reações a essa tirania, como forma de autodefesa ou mesmo vingança. Tal consideração parece dar a dimensão exata da postura de D. Anita que, subitamente, altera seu comportamento.

Se em "Feliz aniversário" há o silenciamento social da personagem, invisível aos olhos da própria família, "Senhor Diretor", de Fagundes Telles, publicado em Seminário dos ratos, apresenta outra perspectiva. É a protagonista quem se silencia, reprimindo sua sexualidade. A narração em $3^{a}$ pessoa, entremeada em alguns momentos pelo discurso indireto livre pelo qual o leitor tem acesso aos pensamentos da protagonista, Maria Emília, que se autodescreve "professora aposentada, paulista, solteira", nos leva a conhecer uma senhora que tem 62 anos e é virgem. A personagem escreve uma carta mental ao "diretor" de um jornal sobre as mazelas que vêm sendo expostas nas capas de revista, por meio da exposição de corpos seminus, e denuncia a "poluição da alma" que assola o ser humano na atualidade. Pensando com Ricardo Piglia em "Teses sobre o conto", percebe-se que a tal carta fictícia é, na verdade, um subterfúgio para a autorreflexão (a segunda história mencionada por Piglia), confirmada pelo desfecho: "Acabei falando em outras pessoas, em mim [...]. Antes e acima de tudo, Senhor Diretor. Senhor Diretor: Senhor Diretor:" (Telles, 1998a, p. 29).

A superexposição a corpos jovens e sexualizados leva a personagem a pensar em como sua vida foi vazia de afeto e de prazer: "Desespero na escassez. Desespero no excesso. Não tive ninguém, mas Mariana exorbitou: três maridos sem falar nos amantes" (Telles, 1998a, p. 19). Enquanto o corpo de Maria Emília é a carta não escrita, o corpo não tocado, Mariana é a amiga que resiste ao envelhecimento, e se degrada pelo excesso, pela busca frenética por saciar seus desejos - tal como Cândida Raposo, de "Ruído de passos", de Clarice Lispector, que decide consultar um médico porque, aos 81 anos, "seu desejo de prazer não passava" (Lispector, 1974, p. 69). No conto de Fagundes Telles, aparece ainda uma terceira amiga, Elza, a qual demonstra o quão ambivalente pode ser o processo de envelhecimento para uma mulher:

Outra vítima da publicidade, a querida Elza. Lastimava tanto a agitação de Mariana, se gabava de aceitar a velhice sem resistência, a pobre querida. Mas tanto ouviu contar das rainhas e estrelas de cinema chegando de longe para renovar a cara, que acabou se impressionando, era muito impressionável. [...] Quando me debrucei no caixão é que entendi tudo, a querida, a pobre querida com a cara toda pincelada de mercurocromo. [...] O consolo é que ela morreu bastante remoçada, a tonta da Mariana veio me dizer na missa (Telles, 1998a, p. 19-20).

A mídia e a publicidade, recheadas de discursos em prol do rejuvenescimento, acabam por impactar as escolhas da personagem. Elza, aparentemente conformada com a passagem do tempo, acaba cedendo às pressões sociais e morre realizando uma cirurgia plástica. Se Maria Emília, por um lado, não cede a tais discursos, nota-se que é fortemente por eles influenciada, uma vez que o não exercício da sexualidade a leva o tempo todo a pensar nisso. O corpo disciplinado pelas regras sociais e interditado ao prazer também não encontra felicidade, e a frustração dá o tom de seu relato.

No dia do aniversário de Maria Emília, ela se permite vivenciar a experiência da multidão - vai ao cinema sozinha - e, ainda que esteja em meio a todos, está completamente solitária. No entanto, recusa o estereótipo da tia velha cercada por sobrinhos tal como a personagem Alice de Quarenta dias, de Maria Valéria Rezende, que tenta desesperadamente fugir ao estereótipo da mulher velha que termina a vida cuidando dos netos. Maria Emília permite-se um momento de deleite no cinema - uma camélia vermelha na lapela do casaco dá um tom sugestivo de transgressão -, mas isso não é o suficiente para alterar a condição de sua vida e de seu corpo, este disciplinado e agora envelhecido. 
Sob outra perspectiva, a do silenciamento social propriamente dito, tem-se o conto "Viagem a Petrópolis", de Clarice Lispector, publicado em A legião estrangeira. Mocinha era "uma velha sequinha que, doce e obstinada, não parecia compreender que estava só no mundo" (Lispector, 2016, p. 316). Mortos marido e filhos, saíra do Maranhão para o Rio de Janeiro ajudada por uma senhora que prometera colocá-la em um asilo, promessa que não se cumprira. Passa então a viver nos fundos de uma casa em Botafogo, sob a guarda de uma família que, um dia, resolve mandá-la embora. A presença de Mocinha incomodava a todos, como um despojo sem função de que pretendiam se livrar. O único prazer de sua vida consistia em pequenos passeios que realizava cotidianamente pela cidade. Um dia, porém, colocam-na num carro rumo a Petrópolis, para que morasse com um irmão com o qual não se davam bem. Na noite anterior à viagem, Mocinha custara a dormir, imersa na expectativa pelo desconhecido, pela grande viagem - expectativa pela morte? - e imersa em lembranças.

Chegando lá, a família não a aceita. Sem lugar para ficar, sem a menor possibilidade de reinserção social - pois era por todos tratada como um trapo, como uma indigente, o que reforça a invisibilidade social a que estava submetida -, ela empreende então seu último passeio:

A estrada subia muito. A estrada era mais bonita que o Rio de Janeiro, e subia muito. Mocinha sentou-se numa pedra que havia junto de uma árvore, para poder apreciar. O céu estava altíssimo, sem nenhuma nuvem. E tinha muito passarinho que voava do abismo para a estrada. A estrada branca de sol se estendia sobre um abismo verde. Então, como estava cansada, a velha encostou a cabeça no tronco da árvore e morreu (Lispector, 2016, p. 324).

A morte de Mocinha é narrada com cores poéticas, mas tem um tom marcadamente seco ao mesmo tempo. Como se, a ela, só restasse, de fato, a morte física, pois há tempos já se encontrava morta socialmente.

\section{O corpo envelhecido redimido}

Em "Boa noite, Maria", conto de Fagundes Telles publicado em A noite escura e mais eu, uma mulher de negócios rica, Maria Leonor, de 65 anos, conhece um estranho em um aeroporto, Julius, e decide que ele será seu companheiro. Ao mesmo tempo que a personagem sente falta de uma presença masculina em sua vida, já não pretende atender às pressões sociais:

Tanto cansaço, um cansaço que vinha de longe, tanta preguiça. Ter que entrar novamente na humilhante engrenagem do rejuvenescimento, que mão de obra. Era alto demais o preço para escamotear a velhice, neutralizar essa velhice - até quando? Por favor, quero apenas assumir a minha idade, posso? Simplesmente depor as armas, coisa linda de se dizer. E fazer. O tempo venceu, acabou. Até que chegou a reagir, recorreu a uma plástica, coisa leve, tinha quarenta anos e um amante vaidoso, Mas querida, você precisa de uma refrescada! A expressão estava na moda, refrescada. Obedeceu. Mas depois desse Augusto veio o Horácio. Ou foi o Rafael? E as insinuações recomeçando (Telles, 1998b, p. 64-65).

$\mathrm{Na}$ passagem, o peso social do envelhecimento fica evidente: recorrer a plásticas significava tentar adequar-se aos padrões de beleza vigentes, não reconhecendo a naturalidade de um processo que é biológico, afinal. Julius, um finlandês sem família, sem raízes, passa a dividir o apartamento com ela e acabam se envolvendo. O enlace sexual é retratado por meio de uma bela cena, que culmina no gozo final:

Nunca sentira antes esse prazer assim desvairado, Julius, Julius! Ficou repetindo. [...] fez a pergunta frívola [...] Então, Julius, vai querer me ver remoçada? Alguma sugestão? Ele demorou para responder. Afagou-lhe os cabelos. A sua beleza vem de dentro, Maria. Não se preocupe, ela resiste (Telles, 1998b, p. 75).

A descoberta tardia do próprio corpo chega quando ela decide não mais se render às convenções sociais, e simplesmente viver, apesar do processo de adoecimento progressivo. $\mathrm{O}$ final do conto é em aberto: não se sabe se ela somente adormeceu, ou se, finalmente, ele lhe poupara o sofrimento que a doença degenerativa lhe causava, retirando os movimentos das pernas. Ao longo do conto, há a sugestão de que ela procurava alguém capaz de praticar a eutanásia - "a 
verdade é que estava só e precisando de alguém que a ajudasse a viver. E a morrer, quando chegasse a hora de morrer" (Telles, 1998b, p. 69). Tal possibilidade parece concretizar-se ao final, quando ela vai entrando em sono profundo, após tomar uma taça de vinho. Para a personagem, viver sem plenitude não valia a pena. Por isso, há uma dupla possibilidade de redenção no conto: o corpo redimido por uma relação que começa como amizade e culmina naturalmente em uma relação homem-mulher, e a própria morte, uma libertação do sofrimento físico, já que a vida caminhando para um estado vegetativo afigurava-se como uma amarra. Nota-se que, apesar de Julius ser mais novo que Maria Leonor - tinha no máximo 50 anos, ao passo que ela, 65 -, a relação por eles vivida ultrapassa o que é socialmente esperado. Diferentemente, por exemplo, de Maria Angélica de Andrade do conto "Mas vai chover?", de Clarice Lispector, publicado em A via crucis do corpo, em que a protagonista tem 60 anos e um amante de 19, o que faz com que ela sacie todas as ambições dele sendo, por fim, abandonada. Observa-se que, em todos os contos estudados, há uma imbricação entre velhice e solidão, velhice e morte.

Como mais um exemplo desse corpo envelhecido redimido, para finalizar, tem-se breve comentário sobre o romance Quarenta dias, de Maria Valéria Rezende, que narra a história de Alice, uma professora aposentada que não queria abrir mão de sua vida na Paraíba para mudar-se para Porto Alegre a fim de ajudar a filha, Norinha, que pretendia ser mãe e, para isso, contava com o fato de que a mãe/futura avó tomasse conta do bebê para que ela pudesse seguir com sua carreira. O livro problematiza a figura estereotipada da "mulher velha", que, socialmente, é quase sempre limitada pelos outros às funções de avó. A própria escritora, freira desde os 24 anos de idade (hoje tem mais de 70), que tem uma história de luta contra a ditadura, transgrediu ao se tornar freira e romper, de algum modo, com o papel que lhe era imputado e previsto socialmente, a saber, o de mulher "do lar". Em entrevista ao jornal Estado de São Paulo, afirma:

Era um tempo em que o mundo fazia a seguinte pergunta para as meninas: "Quer casar ou vai ser freira?" A ideia de vida para a maioria era casar, ter um único emprego, viver na mesma cidade, criar um monte de filhinho. Depois de tanta aventura eu ia virar dona de casa? Não (Rezende, 2014).

Tal postura questionadora dos padrões vigentes aparece, de algum modo, reelaborada no romance em xeque. Alice acaba cedendo às pressões da filha e da família de um modo geral e, mal chegara no Sul, descobre que Norinha e o genro passariam seis meses no exterior. Absolutamente sozinha em uma cidade na qual não conhecia ninguém, ela permanece perambulando na rua por 40 dias, em busca do paradeiro de um certo Cícero, filho de uma conhecida na Paraíba que fora trabalhar lá e desaparecera. Nessa busca quase fictícia - procurálo se torna cada vez mais um pretexto, uma fuga à realidade em que se encontrava -, em que modificava e aumentava os detalhes da história para comover os outros, Alice conhece uma outra cidade, cheia de becos, vielas e maltrapilhos, ao mesmo tempo que tal peregrinação traz à tona um processo de redescobrimento/autoconhecimento. Em uma narração que se aproxima do fluxo de consciência, Alice narra sua história para um caderno em cuja capa aparece a figura da Barbie, uma interlocutora também fictícia. Admitir para si própria a manipulação sofrida por parte de Nora, narrando sua fuga pelas ruas de Porto Alegre, é uma forma de resistência, ainda que silenciosa e invisível. Assim, o corpo envelhecido redime-se de algum modo, na medida em que a personagem transgride ao viver uma aventura que somente seu diário e as personagens anônimas e invisíveis de uma outra Porto Alegre conhecem.

Portanto, como se pretendeu demonstrar ao longo deste trabalho, as representações do corpo envelhecido são diversificadas na literatura de autoria feminina, mas todas apontam, de algum modo, para a solidão e o lugar de subalternidade por ele ocupado na sociedade. Assim, a literatura nos permite, então, refletir sobre essa situação para, quem sabe, ressignificá-la em nosso cotidiano. 


\section{Referências}

AGAMBEN, Giorgio (2009). O que é o contemporâneo? e outros ensaios. Chapecó: Argos.

BEAUVOIR, Simone de (1990). A velhice. 3. ed. Rio de Janeiro: Nova Fronteira.

BOSI, Ecléa (1987). Memória e sociedade: lembranças de velhos. 2. ed. São Paulo: USP.

BRASIL. Secretaria de Direitos Humanos. Dados sobre o envelhecimento no Brasil. 2014. Disponível em: www.sdh.gov.br. Acesso em: 15 fev. 2018.

CHAUI, Marilena (1984). Repressão sexual: essa nossa (des)conhecida. São Paulo: Brasiliense.

DALCASTAGNÈ, Regina (2005). A personagem do romance brasileiro contemporâneo: 1990-2004. Estudos de Literatura Brasileira Contemporânea, Brasília, n. 26, p. 13-71, jul./dez.

LISPECTOR, Clarice (2016). Feliz aniversário. In: LISPECTOR, Clarice. Todos os contos. Rio de Janeiro: Rocco. p. 179-192.

LISPECTOR, Clarice (2016). Viagem a Petrópolis. In: LISPECTOR, Clarice. Todos os contos. Rio de Janeiro: Rocco. p. 316-324.

REZENDE, Maria Valéria (2014). Maria Valéria viveu na rua para escrever romance. O Estado de São Paulo, São Paulo, Caderno Cultura, 2 mai. Disponível em: http://cultura.estadao.com.br/noticias/geral,mariavaleria-rezende-viveu-na-rua-para-escrever-romance,1161541. Acesso em: 20 fev. 2018.

TELLES, Lygia Fagundes (1998a). Seminário dos ratos. Rio de Janeiro: Rocco.

TELLES, Lygia Fagundes (1998b). A noite escura e mais eu. Rio de Janeiro: Rocco.

TELLES, Lygia Fagundes (1999a). As horas nuas. Rio de Janeiro: Rocco.

TELLES, Lygia Fagundes (1999b). Antes do baile verde. Rio de Janeiro: Rocco.

XAVIER, Elódia (2007). Que corpo é esse? O corpo no imaginário feminino. Florianópolis: Editora Mulheres. 